\title{
Implementation of a Professional Society Core Curriculum and Integrated Maintenance of Certification Program
}

Authors:

${ }^{*}$ Carlos WG ${ }^{1}$, "Poston $\mathrm{JT}^{2}$, Michaud GC ${ }^{3}$, Dela Cruz CS ${ }^{4}$, Luks AM ${ }^{5}$, Boyer $\mathrm{D}^{6}$, Moore $\mathrm{PE}^{7}$, McSparron $\mathrm{Jl}^{8}$, Hayes $\mathrm{MM}^{9}$, Balachandran $\mathrm{JS}^{10}$, Wang $\mathrm{TS}^{11}$, Larsson $\mathrm{E}^{12}$, Siegel-Gasiewski ${ }^{13}$, Kantz, $\mathrm{A}^{14}$, Beck $\mathrm{JM}^{15}$, Thomson $\mathrm{CC}^{16}$

1 W. Graham Carlos, MD, MSCR: Division of Pulmonary and Critical Care, Department of Medicine, Indiana University School of Medicine, Indianapolis IN 1 Jason Poston MD: Section of Pulmonary and Critical Care Medicine, Department of Medicine, University of Chicago

3 Gaetane Michaud Md, MS; Division, Pulmonary, Critical Care and Sleep Medicine, New York University School of Medicine, New York, NY

4 Charles S. Dela Cruz, MD PhD; Section of Pulmonary, Critical Care and Sleep Medicine, Department of Medicine, Yale University School of Medicine, New Haven, CT

5 Andrew M. Luks, MD: Division of Pulmonary and Critical Care Medicine. University of Washington School of Medicine. Seattle, Washington 6 Debra Boyer, MD: Division of Respiratory Diseases. Boston Children's Hospital, Boston, MA

7 Paul E Moore, MD: Division of Pediatric Allergy, Immunology, and Pulmonary Medicine, Department of Pediatrics, Vanderbilt University Medical Center, Nashville, TN

8 Jakob I McSparron, MD: Division of Pulmonary, Critical Care, and Sleep Medicine, Department of Medicine, Beth Israel Deaconess Medical Center, Harvard Medical School, Boston, Massachusetts

9 Margaret M. Hayes, MD Division of Pulmonary, Critical Care, and Sleep Medicine, Department of Medicine, Beth Israel Deaconess Medical Center, Harvard Medical School, Boston, Massachusetts

10 Jay S Balachandran: Section of Pulmonary and Critical Care Medicine, Columbia St. Mary's Hospital, Milwaukee, Wisconsin

11 Tisha Wang, MD: Division of Pulmonary and Critical Care, Department of Medicine, David Geffen School of Medicine at UCLA, Los Angeles CA

12 Eileen Larsson: American Thoracic Society, New York, New York

13 Jennifer Siegel-Gasiewski: American Thoracic Society, New York, New York 14 Alan Kantz: American Thoracic Society, New York, New York

15 James M. Beck, MD: Division of Pulmonary Sciences and Critical Care Medicine, Department of Medicine, University of Colorado School of Medicine, Aurora $\mathrm{CO}$

16 Carey Thomson, MD, MPH: Division of Pulmonary and Critical Care, Department of Medicine, Mount Auburn Hospital, Harvard Medical School, Boston MA

${ }^{*}$ Co-first authors 
Contact information (corresponding author):

W. Graham Carlos MD, MSCR

720 Eskenazi Avenue, H6-510

Indianapolis, Indiana 46202

Ph: 317-691-8107

Email: wcarlos@iu.edu

Source of support: none

Running head: Implementation of Core Curriculum

MESH key words: training, education, certification

Word Count: 2,882 


\begin{abstract}
Medical professional societies exist to foster collaboration, guide career development, and provide continuing medical education opportunities. Maintenance of certification is a process by which physicians complete formal educational activities approved by certifying organizations. The American Thoracic Society (ATS) established an innovative maintenance of certification program in 2012 as a means to formalize and expand continuing medical education offerings. This program is unique as it includes explicit opportunities for collaboration and career development in addition to providing continuing medical education and maintenance of certification credit to society members. In describing the development of this program referred to as the "Core Curriculum", the authors highlight the ATS process for content design, stages of curriculum development, and outcomes data with an eye towards assisting other societies who seek to program similar content. The curriculum development process described is generalizable and positively influences individual practitioners and professional societies in general, and as a result, provides a useful model for other professional societies to follow.
\end{abstract}




\section{Introduction}

The American Thoracic Society (ATS) is an international professional society of more than 15,000 members focused on advancing research and clinical care in adult and pediatric pulmonary disease, critical care, and sleep medicine. Over the past five years the ATS developed a Core Curriculum (Core) linked to opportunities to meet maintenance of certification (MOC) requirements for both the American Board of Internal Medicine (ABIM) and the American Board of Pediatrics (ABP). The ATS was the first professional society in the field of pulmonary and critical care medicine to offer such a program and can serve as a model for other societies developing similar programs to meet the needs of their members. This manuscript will describe the creation and implementation timeline of the ATS Core Curriculum with particular attention to guiding principles (Figure 1) that will aid other societies now launching similar initiatives to meet the needs of their members ${ }^{1}$.

\section{Background}

MOC activities exist for physicians to demonstrate competence to certifying organizations and remain current in their knowledge and clinical skills, fostering a commitment to lifelong learning and professionalism.

Unfortunately, opportunities to obtain MOC credit are limited and, when available, often come at an additional cost to the learner. Additionally, MOC products can 
be time-consuming to complete ${ }^{2}$. The ATS addressed these barriers in developing the Core, pairing the sessions with the society's annual international conference and allowing participants to obtain MOC credit at no additional cost.

The ATS is rooted in an infrastructure of fourteen assemblies, resulting historically in a "grass-roots" or "bottom-up" educational agenda and programming. To establish this Core Curriculum linked to MOC and integrate it into the conference, a culture shift was necessary. In 2010, the Accreditation Council of Continuing Medical Education (ACCME) recommended that the ATS develop a "top-down" or centrally controlled educational program in addition to its grass-roots process. This was to ensure that ATS programming represented the full breadth of pulmonary, critical care, and sleep medicine. That same year, the $A B P$ revised its $M O C$ requirements to include continuous demonstration of competence in recurring 5-year certification cycles. Shortly thereafter, the ABIM required that physicians complete MOC activities every 2 years and demonstrate clinical competence on a 5-year MOC cycle. In response to the ACCME's feedback and the changes in MOC requirements, the ATS performed a comprehensive needs assessment of its educational programs that lead to the creation of the Core to meet the clinical content and MOC needs of our members who are certified through the ABIM and/or ABP.

In establishing the Core, collaboration and support from across the ATS was critical. Multiple existing ATS committees (Education, Executive, International 
Conference) and the ATS Board of Directors played a role in helping conceptualize, operationalize, and evaluate the $\mathrm{Core}^{3-5}$. This collaboration provided the framework for formation of the specific content and topics to be covered. Once established, the content and topics were categorized into the following tracks: Adult Pulmonary, Adult Critical Care, Sleep, and Pediatric Pulmonary Medicine.

A critical component of this process was working collaboratively with the accrediting and certifying organizations of the society's membership. The rapidly evolving arenas of continuing medical education and $\mathrm{MOC}$ require that professional societies anticipate and adapt to the needs of its members. Furthermore, many societies, like the ATS, have members certified by multiple organizations with different MOC requirements. Collaboration with the ACCME, the $A B P$, and the $A B I M$ has been instrumental to the inception, development, and evolution of the Core program.

\section{History of the Core}

\section{Pilot Program: The 2012 Adult Pulmonary Core}

The first iteration of the Core was a pilot program in adult pulmonary medicine offered at the ATS International Conference in 2012. This pilot included a summary of recent advances in seven high yield pulmonary medicine topics based on the ABIM's blueprint for the MOC 10-year examination. The ATS Education Committee partnered with selected speakers to develop a set of thirty 
novel MOC questions that were approved by the ABIM in advance of the International Conference. These questions provided an organizational framework to the presentations at the International Conference Core sessions, and participants who attended this pilot and successfully completed the postcourse MOC questions received 10 points of $A B I M$ MOC credit. In our pilot year we had 47 participants complete both pre and post testing. Their scores improved by an average of $22 \%$.

\section{Expansion and Replication of the Core Curriculum}

Based on the successful implementation of the pilot program, the Core was expanded for the 2013 ATS International Conference to include offerings in all four tracks (Adult Pulmonary, Adult Critical Care, Sleep, and Pediatric Pulmonary Medicine). The curriculum was delivered in lecture format over multiple sessions (totaling 3.5 to 4 hours per track) and was linked to MOC questions yielding between 10-13 MOC points per track. The 10 or more MOC points per track were targeted to allow ATS clinicians who care for adults, who typically practice and would likely participate in 2 Core tracks, to achieve $20 \mathrm{MOC}$ points annually. This would allow this clinician to fully satisfy the medical knowledge MOC requirements of the $\mathrm{ABIM}$ (100 points every five years). Pediatric pulmonologists participating the Core could achieve 10 points annually, fully satisfying the lifelong learning and self-assessment $M O C$ requirements of the $A B P(40$ points every 5 years). A pre-test including the MOC questions was made available to learners prior to the start of the International Conference. The didactic sessions 
took place in large conference rooms where attendees were given hard copies of the MOC questions upon entering the room. The sessions reviewed major topics in the field and recent advances, as well as discussed the MOC questions and their respective answers. Following the sessions, an online post-test utilizing the same questions was made available for MOC points $(A B I M)$ or credit $(A B P)$ provided a passing score was achieved $(80 \%$ for Pediatrics, $70 \%$ for other pillars). These sessions were strategically programmed to avoid competition with other high-profile conference offerings. Announcements about the Core were provided just before and during the conference.

Anticipating the program to be an annual offering, members of the ATS Education Committee elected to offer the core curriculum over a recurring 3-year cycle (or 4 years in the case of Pediatrics). The topics were selected based on the MOC blueprints of the relevant certifying organizations. This schedule was intended to allow adequate depth for each topic, to ensure that no topic was presented less frequently than every three years, and to allow the lectures to serve as clinical practice updates for clinicians and researchers.

Imperative to success was a society-wide consensus regarding the vision, goals, and commitment to offering a comprehensive MOC program. The introduction of multiple Core symposia sessions minimally reduced the number of International Conference sessions the fourteen individual Assemblies were able to program in 
the historical "bottom-up" fashion. It was critical that the Core was seen as an important society-wide initiative central to its clinical and educational mission.

To address the needs of members who could not attend the International Conference, the Education Committee subsequently expanded the scope of the Core $^{3}$. Starting with the 2014 Core, the Education Committee partnered with Annals of the ATS to develop a unique publication series based on the Core. Summaries of each talk authored by the International Conference speakers were assembled by an editorial team into a four-part series and published by Annals of the ATS. Web links within these publications enable ATS members to obtain both continuing medical education and $\mathrm{MOC}$ credit for mastering the content of the articles ${ }^{3,6^{-9}}$. This method of learning and obtaining MOC has been very popular as evidenced by the number of views and downloads of the publications and abstracts. From 2014 until the time of this writing the twelve Core publications for the combined tracks have been viewed nearly 15,000 times and downloaded over 5,000 times and have frequently been the most downloaded and viewed articles of the month.

\section{Annual Core Content Creation and Delivery}

Delivering the Core content annually requires thoughtful leadership, attentive administration, rigorous adherence to timelines, and diligence on the part of motivated society committee members and staff. The process of developing content begins a year prior to the International Conference. A working group for 
each of the four Core tracks is formed within the Education Committee to review the anticipated content based on the 3 or 4-year curriculum cycle and determine the specific topics for the upcoming year. Nominations for contributors are solicited from ATS leadership, fellowship program directors, division chiefs at institutions around the world as well as additional ATS society members. The Core working groups then select and invite individual contributors based on nominations that outline their reputation as outstanding educators, content expertise, previous evaluations of speaking experience, presentation skills, and writing abilities. To foster early career development, contributors are asked to partner with junior faculty or senior fellows to develop materials related to their presentation and publication. Contributors are required to adhere to a tight timeline in producing three deliverables: the international conference lecture, an accompanying summary publication for Annals of the ATS, and at least five best answer multiple choice questions to be addressed in the lecture and article as part of the MOC product.

Each of these deliverables is peer reviewed by members of Education Committee working groups, who also serve as the section editors for the Annals of the ATS manuscript. The peer-review process is critical as there are specific format requirements that are generally unfamiliar to most contributors. Peerreviewers work iteratively to ensure that questions adhere to guidelines from the $A B I M$ and $A B P$ and are explored in the content of the lecture and article. The timeline is necessary for the complex process of writing, editing, and revising of 
all four products to create an integrated product, paired with adequate time for review and approval of the MOC questions.

The process of writing, editing, and approval of multiple choice questions for MOC has evolved under the oversight of the ABIM. Previously, questions were developed up to one year in advance of the International Conference to allow for the ABIM's review and approval process. This process precluded the inclusion of novel information published in the year leading up to the conference, and created challenges in delivering the most up to date MOC content. In 2015, the ABIM partnered with the ACCME to offer MOC and created a pathway for societies experienced in CME and MOC development to be certified as MOC providers. This has shortened the timeline considerably and has allowed the ATS to develop MOC content alongside the more current and scientifically rigorous journal publications and International Conference presentation series, including the Core. While the process of selecting contributors still begins 9 months prior to the International Conference, the Annals of the ATS summaries are now written 5-8 months prior to the conference and changes to the lecture and MOC question content resulting from that editorial process can be made until 8-12 weeks prior to the International Conference.

As the Core has evolved, it has become more efficient, but still requires a significant time commitment for those charged with planning, coordinating, editing, and integrating the materials. Each year approximately 28 peer-reviewed 
lectures are created along with 4 compilation articles and $120 \mathrm{MOC}$ multiple choice questions. This scholarship effort requires strong leadership, administrative support, and collaboration.

\section{Career advancement and scholarship}

The Core has provided unique opportunities for faculty development by rewarding contributors with academic currency for their efforts. Rather than rely on senior level experts to develop and present the primary content, we have relied primarily on early to mid-career content experts who are excellent educators and writers. The invitation to participate comes with high expectations, but also offers a speaking invitation at an international conference and scholarly credit for contributing to enduring educational products. Speakers also have the opportunity to work with and mentor more junior colleagues. Together, these benefits have assisted ATS efforts to recruit and retain outstanding faculty and established a pipeline for outstanding educators who are invested in the society.

\section{Results}

Little information is known regarding the participants in Adult or Pediatric Pulmonary, Critical Care and Sleep MOC specifically. The only data regarding those who engage in MOC in general are extrapolated from the Internal Medicine recertification process. Physicians who completed MOC in Internal Medicine are younger and primarily US medical graduates practicing as subspecialists in group practices. They reported placing a higher priority on patient care, followed 
by teaching, administration and research and commonly work in affluent environments (less than $20 \%$ poverty in their respective counties). In addition, participants in Internal Medicine MOC demonstrate above average certification examination scores ${ }^{2,10}$.

Attendance at Core Curriculum symposia at the ATS International Conference has not been directly measured but it is estimated to have grown from 150 to over 1500 people in 2016 based on the room size now needed to accommodate attendees. The effectiveness of the Core was evaluated using pre and post-tests assessing knowledge. Although submission of a pre-test was not required for MOC credit (only passing of the post-test was required) a number of participants completed both offerings allowing for an assessment of change in knowledge. Paired t-tests comparing mean pre and post course knowledge assessments demonstrated improvements on the post-test across each of the tracks when compared to performance on the pre-test (Table 1). In 2016, we noted a reduction in the number of individuals completing MOC testing. While this was unexpected, we believe it was most likely related to evolving ABIM MOC credit requirements, practitioners' establishing new habits with regard to ABIM MOC management (at least one MOC activity required every other year), and the emergence of other MOC opportunities within ATS programming and publications. Most participants claimed MOC credit after passing the post-test (Table 2). 
All Core Curriculum sessions have garnered positive evaluations. On a 5 point Likert scale $(1=$ strongly disagree, 2 = disagree, $3=$ neutral, $4=$ agree, $5=$ strongly agree) all sessions have averaged above 4 to the following questions regarding their quality: met their identified objectives, were scientifically rigorous and balanced, addressed important gaps in knowledge in the field, and were free of bias. Numerous participants also stated in free response comments that the Core content and the opportunity for MOC credit improved their experience at the ATS International Conference and were the primary reason for attending the meeting. The value of the Core is also evidenced by the participation of members who do not complete the MOC component, and that of international members not required to complete MOC modules like their North American counterparts.

\section{Additional MOC Products}

As the Core has expanded its reach, the ATS has also taken steps to provide MOC through other means. The ATS Clinical Practice Guidelines Summary for Clinicians links additional MOC opportunities to a published series in Annals of the ATS. Working in conjunction with the Education Committee, Document Development Implementation Committee, and the Quality Improvement and Implementation Committee, ATS members write high-yield two-page clinical summaries of more in-depth ATS clinical practice guidelines and technical standards. These summaries are linked to a 30 multiple choice question MOC module and offer $10 \mathrm{ABIM}$ or ABP MOC points similar to the Core. This aids in 
the delivery of new information and MOC to ATS members ${ }^{11}$. Through the Core and other initiatives, the ATS has made available 331 ABIM MOC points and 130 ABP points between 2012 and 2016 . These programs have helped greatly in meeting the educational needs of its membership while concurrently providing MOC for its US members as a standard benefit of ATS membership.

\section{Future Directions}

The ATS Core Curriculum has met the needs of members through strategically programming a rotating content cycle for Adult Pulmonary, Critical Care, Sleep, and Pediatric Pulmonary and offering the opportunity for MOC. Participation in the Core has grown substantially as evidenced by increases in attendance at the International Conference and readership of the Annals of the ATS series.

Participation seems to be enhanced by the availability of the MOC, but the value to members exceeds the MOC. Over a third of those attending the Core sessions did not participate in the MOC program, suggesting the content is valuable to those receiving credit through other international governing bodies such as the Royal College of Physicians and Surgeons of Canada. Participants view these activities as adding value to their ATS membership and conference experience. Attendance suggests that our feedback to date likely underestimates the number positively impacted by the availability of this rich resource. 
A formal needs assessment to identify Core participants and drivers to partake in this educational opportunity is underway to ensure that ATS programming continues to provide our members with appropriate MOC and CME products, particularly within an evolving certification landscape which presents opportunities and challenges. The ability to reach the entire membership, regardless of their ability to attend the International Conference, is essential to the ongoing success of this program, and are working to develop interactive, web-based opportunities for Core. The ultimate goal is to be able to measure improvement in performance on certification and recertification examinations and to demonstrate an impact on practice quality, which aligns with the goals of most MOC programs.

In summary we hope this description of the evolution and impact of the Core will assist other professional societies who seek to incorporate MOC opportunities into their mission, publications, and conference programming.

\section{Acknowledgements, Funding, Disclaimers, Ethical Approval}

Acknowledgments: The authors would like to thank David Au, Steve Crane, John Hansen-Flaschen for their help in the development of this program. 


\section{References}

1. Chazal RA. ABIM Maintenance of Certification Current Status. J Am Coll Card 2016;67(21):2547-2549.

2. Lipner RS, Bylsma WH, Arnold GK, Fortna GS, Tooker J, Cassel Ck. Who is maintaining certification in internal medicine-and why? A national survey 10 years after initial certification. Annals of Internal Medicine 2006;144(1):29-36.

3. Thomson CC, Hansen-Flaschen J. Editor's Introduction to the ATS CORE Curriculum Series. Ann Amer Thorac Soc 2014.11(7):10861087.

4. Hill NS, Schraufnagel D, Curtis JR. Why PATS to ANNALSATS? Ann Am Thorac Soc 2013;10:53.

5. Hansen-Flaschen J. The New ATS journal for clinicians. Ann Am Thorac Soc 2013;10:54-55.

6. *Nyendak ME, Lewinsohn DM, *Shah DR, Wunderink RG, *Koch CD, Moris A, *McDade KE, Michaud GC, *Mahajan AK, Channick CL, *Argento AC, Wahidi MM, *Beckett WS, George G, Thomson CC. ATS 
Core Curriculum 2014: Part I. Pulmonary. Ann Am Thorac Soc 2014; 11(7):1136-1144.

7. Michaud GC, Channick CL, Marion CR, Tigh RM, Town JA, Luks AM, Richards JB, Kher S, Mota P, Hong G, West NE, Rackley C, Neilans L, Rodriguez-Lopez J, DuBrock H, Kennedy CC, DJ, Carey C. Thomson. ATS Core Curriculum 2015: Part I: Adult Pulmonary Medicine Core Curriculum. Ann Amer Thorac Soc 2015;12(9):1387-1397.

8. Boyer D, Nevin M, Thomson CC, Sanders DB, Stamatia A, Goldfarb SB, Nicholas JL, Thackers PG, Coverston AM, Faro A, Cheng G, Adnan M, Moore PE. Core Curriculum Part III: Pediatric Pulmonary Medicine. Ann Amer Thorac Soc 2015;12(11):1688-1696.

9. Poston JT, McSparron JI, Hayes MM, Damm T, Patel JJ, Decker BK, Attia EF, Coruh B, Cai X, K WT, Poisson SN, Sokol S, Csikesz N, Levinson AT, Thomson CC, Luks AM. ATS Core Curriculum Part IV. Adult Critical Care Medicine. Ann Amer Thorac Soc 2015;12(12): 18641872.

10. Lipner RS, Brossman BG. Characteristics of internal medicine physicians and their practices that have differential impacts on their maintenance of certification. Academic Medicine 2015;90(1):82-87. 
11. Carlos WG, Strek ME, Wang TS, Patel H, Raghu G, Wilson KC, Thomson CC. Clinical Practice Guidelines: Summary for Clinicians. Treatment of Idiopathic Pulmonary Fibrosis. Ann Am Thorac Soc 2016;13(1):115-117. 
1. Build society-wide consensus regarding the vision, goals, and commitment to offering a comprehensive MOC program.

2. Work collaboratively and proactively with the accrediting and certifying organizations of the society's membership.

3. Establish strong leadership, administrative support, and a strict timeline.

4. Utilize multiple media to expand the accessibility and impact of the program.

5. Consider MOC program development as an opportunity for faculty development, and reward contributor effort with academic currency. 
Table 1. 2013-2016 paired pre and post-test scores for Core Curriculum Maintenance of Certification test participants for each Core track and combined ( $P$ value $<0.05$ statistically significant).

\begin{tabular}{|c|c|c|c|c|c|}
\hline Pulmonary & $\mathrm{N}$ & $\begin{array}{c}\text { Pre-Test } \\
\text { mean score }\end{array}$ & $\begin{array}{c}\text { Post-Test } \\
\text { mean score }\end{array}$ & Difference & P value \\
\hline 2013 & 47 & $71 \%$ & $87 \%$ & $16 \%$ & $<0.01$ \\
\hline 2014 & 87 & $45 \%$ & $84 \%$ & $39 \%$ & $<0.01$ \\
\hline 2015 & 53 & $67 \%$ & $84 \%$ & $17 \%$ & $<0.01$ \\
\hline 2016 & 28 & $51 \%$ & $82 \%$ & $31 \%$ & $<0.01$ \\
\hline
\end{tabular}

\begin{tabular}{|c|c|c|c|c|c|}
\hline Critical Care & N & $\begin{array}{c}\text { Pre-Test } \\
\text { mean score }\end{array}$ & $\begin{array}{c}\text { Post-Test } \\
\text { mean score }\end{array}$ & Difference & P value \\
\hline 2013 & 36 & $66 \%$ & $84 \%$ & $18 \%$ & $<0.01$ \\
\hline 2014 & 104 & $61 \%$ & $90 \%$ & $29 \%$ & $<0.01$ \\
\hline 2015 & 199 & $61 \%$ & $91 \%$ & $30 \%$ & $<0.01$ \\
\hline 2016 & 25 & $61 \%$ & $90 \%$ & $29 \%$ & $<0.01$ \\
\hline
\end{tabular}

\begin{tabular}{|c|c|c|c|c|c|}
\hline Sleep & $\mathrm{N}$ & $\begin{array}{c}\text { Pre-Test } \\
\text { mean score }\end{array}$ & $\begin{array}{c}\text { Post-Test } \\
\text { mean score }\end{array}$ & Difference & P value \\
\hline 2013 & 18 & $74 \%$ & $90 \%$ & $16 \%$ & $<0.01$ \\
\hline 2014 & 24 & $71 \%$ & $87 \%$ & $16 \%$ & $<0.01$ \\
\hline 2015 & 20 & $73 \%$ & $88 \%$ & $15 \%$ & $<0.01$ \\
\hline 2016 & 12 & $63 \%$ & $90 \%$ & $27 \%$ & $<0.05$ \\
\hline
\end{tabular}

\begin{tabular}{|c|c|c|c|c|c|}
\hline Pediatrics & $\mathrm{N}$ & $\begin{array}{c}\text { Pre-Test } \\
\text { mean score }\end{array}$ & $\begin{array}{c}\text { Post-Test } \\
\text { mean score }\end{array}$ & Difference & P value \\
\hline 2013 & 52 & $69 \%$ & $96 \%$ & $27 \%$ & $<0.01$ \\
\hline 2014 & 60 & $54 \%$ & $87 \%$ & $33 \%$ & $<0.01$ \\
\hline 2015 & 90 & $61 \%$ & $95 \%$ & $34 \%$ & $<0.01$ \\
\hline 2016 & 34 & $56 \%$ & $98 \%$ & $42 \%$ & $<0.01$ \\
\hline
\end{tabular}

\begin{tabular}{|c|c|c|c|c|c|}
\hline Combined & $\mathrm{N}$ & $\begin{array}{c}\text { Pre-Test } \\
\text { mean score }\end{array}$ & $\begin{array}{c}\text { Post-Test } \\
\text { mean score }\end{array}$ & Difference & P value \\
\hline 2013 & 153 & $70 \%$ & $89 \%$ & $19 \%$ & $<0.01$ \\
\hline 2014 & 319 & $58 \%$ & $89 \%$ & $31 \%$ & $<0.01$ \\
\hline 2015 & 216 & $64 \%$ & $91 \%$ & $27 \%$ & $<0.01$ \\
\hline 2016 & 99 & $57 \%$ & $90 \%$ & $33 \%$ & $<0.01$ \\
\hline
\end{tabular}


Table 2. 2013-2016 core curriculum maintenance of certification post-test participation, success, and credit claimed.

\begin{tabular}{|l|c|c|c|}
\hline \multicolumn{1}{|c|}{$\mathbf{2 0 1 3}$} & Took Post Test & \% Passed & \% Claimed Credit \\
\hline Pulmonary & 77 & 100 & 23 \\
\hline Critical Care & 62 & 100 & 16 \\
\hline Sleep & 34 & 100 & 5 \\
\hline Pediatrics & 86 & 99 & $*$ \\
\hline Total & 259 & 100 & 13 \\
\hline
\end{tabular}

\begin{tabular}{|l|c|c|c|}
\hline \multicolumn{1}{|c|}{$\mathbf{2 0 1 4}$} & Took Post Test & \%Passed & \% Claimed Credit \\
\hline Pulmonary & 205 & 96 & 97 \\
\hline Critical Care & 235 & 96 & 95 \\
\hline Sleep & 83 & 94 & 74 \\
\hline Pediatrics & 102 & 85 & 92 \\
\hline Total & 625 & 94 & 94 \\
\hline
\end{tabular}

\begin{tabular}{|l|c|c|c|}
\hline \multicolumn{1}{|c|}{$\mathbf{2 0 1 5}$} & Took Post Test & \% Passed & \% Claimed Credit \\
\hline Pulmonary & 159 & 97 & 92 \\
\hline Critical Care & 156 & 94 & 92 \\
\hline Sleep & 72 & 96 & 86 \\
\hline Pediatrics & 142 & 99 & 87 \\
\hline Total & 529 & 96 & 90 \\
\hline
\end{tabular}

\begin{tabular}{|c|c|c|c|}
\hline 2016 & Took Post Test & $\%$ Passed & $\%$ Claimed Credit \\
\hline Pulmonary & 113 & 95 & 94 \\
\hline Critical Care & 123 & 93 & 49 \\
\hline Sleep & 70 & 91 & 88 \\
\hline Pediatrics & 106 & 97 & 94 \\
\hline Total & 529 & 74 & 80 \\
\hline Totals & 1413 & 96 & 77 \\
\hline
\end{tabular}

* Not available. 